\title{
An Analysis on Pragmatic Presupposition in Cosmetic Advertising Language of Lancome
}

\author{
Jin Wang \\ School of English for International Business \\ Guangdong University of Foreign Studies \\ Guangzhou, China
}

\author{
Xiaoxiao Chen* \\ School of English for International Business \\ National Experimental Teaching Center of Simultaneous \\ Interpreting \\ Guangdong University of Foreign Studies \\ Guangzhou, China \\ *Corresponding Author
}

\begin{abstract}
Beauty is an eternal theme in a woman's life. With the high-speed development of information technology, all kinds of cosmetic products spring up like mushrooms. Advertisers also spare no effort in perfecting their cosmetic advertisements. Pragmatic presupposition makes the cosmetic advertisements more novel and interesting. Based on pragmatic presupposition, this report examines the characteristics of advertising language of the French brand Lancôme. It also analyzes the impact of pragmatic presupposition on the advertising language and puts forward three functions of pragmatic presupposition concerning cosmetic advertising language. The study aims to enrich the study on the practice of pragmatic presupposition and provide a reference for the effective advertising marketing of cosmetics.
\end{abstract}

Keywords-pragmatic presupposition; cosmetic advertising language; advertising marketingt

\section{INTRODUCTION}

With the amazing development of information technology, women can have access to a dizzying variety of cosmetic brands and products. The cosmetic advertisements always convey meaning such as beauty, young and charm to attract potential consumers. More or less, pragmatic presupposition is deployed in the cosmetic advertising language. Based on this, this report makes a study of the cosmetic advertising language of the French cosmetic brand Lancôme. The purpose of this study is to find out what kind of role pragmatic presupposition plays in cosmetic presupposition. It also aims to enrich the study on the practice of pragmatic presupposition and provide a reference for the effective advertising marketing of cosmetics. All the data are from the English official website of Lancôme and the advertising videos it has issued. The advertisements concerns perfumes, skin care products and so on.

Lancôme is a French luxury perfumes and cosmetics house that distributes products internationally. Lancôme is part of the L'Oréal Luxury Products division, which is its parent company and offers skin care, fragrances, and makeup at higher-end prices. Lancôme was founded in 1935 in France, as originally a fragrance house. The name "Lancôme" was inspired by the forest of Lancosme that lies in the Indre valley in the heart of France in the region of La Brenne. The roses in the area inspired the company's symbol of the single golden rose. The company provides not only fragrances, but also skin care and makeup. Its most famous products include mascaras, namely "Hypnôse", the Visionnaire Range which contains a patented ingredient aimed to improve skin texture qualities, especially in pore reduction, fine lines and uneven skin tone. Lancôme has recently released a new serum called "Dreamtone", which claims to improve on color irregularities including sun spots and blemish marks. The serum is available in three colors, fair, medium and dark to match individual skin tones.

This paper consists of five major sections, each of which gives detailed illustration of the corresponding part. Section 1 is the introduction part. It explains the motivation and purpose of this paper. It also mentions the data resource and provides some basic information of French brand Lancôme. In section 2 , previous studies on pragmatic presupposition and cosmetic advertisements are reviewed. Both the domestic and foreign references are included. In section 3, detailed information is provided on the theoretical framework. It gives a detailed illustration on the definition of pragmatic presupposition and characteristics of it. Section 4 is the data analysis of this study, which is the most important part. It sheds light on how pragmatic presupposition influences the effectiveness of cosmetic advertising language and focuses on three functions of pragmatic presupposition. It also expounds what domestic cosmetics companies should do to make their advertisements attract more customers. Section 5 is the conclusion part. This part not only gives a summary of the results and meaning of this study, but also provides advice on what future work should focus on to contribute to marketing mix strategy in various fields. In addition, it points out the limitation of this study and gives the reasons for the limitation.

\section{LITERATURE REVIEW}

Previous studies on pragmatic presupposition and cosmetic advertisements are rich and varied. The following will give a detailed review on the previous studies about 
pragmatic presupposition and cosmetic advertisements. Both the foreign and domestic studies will be considered.

\section{A. Previous Studies on Pragmatic Presupposition from a Theoretical Perspective}

Previous studies on pragmatic presupposition are rich and assorted. Some analyzes the relation between semantic presupposition and pragmatic presupposition while others use pragmatic presupposition to study subjects in different fields such as advertisement, education and social phenomena.

Kang (2012) makes a detailed study of too in the framework of presupposition. She aims to probe its use as a presupposition trigger bordering in semantics and pragmatics. In doing so, she hopes to solve a great amount of problems that are controversial and have no unified solutions now. From her point of view, too is considered as a pragmatic presupposition trigger in pragmatics. It can express the discriminative meaning in everyday conversation while also plays an essential role in textual organization and information flow in discourse.

Schlenker (2008) holds that the analysis of presupposition projection contributed to a dynamic turn in semantics. He explores an alternative in which presupposition projection follows from the combination of a fully classical semantics with two pragmatic principles of manner. From his perspective, two equivalence theorems guarantee that principles derive Heim's results in almost all cases. He gives a flexible analysis of this incremental bias.

Lanre-Abass (2010) studies the relation between racism and presupposition. He holds that racism has been described as a litmus test which reveals other disorders and injustices within a society. From his point of view, racism presupposes the legitimacy of racial classifications and the metaphysical reality of races and therefore provides a vital area of scrutiny for philosophical traditions. He examines racism and its antisocial effects both on the individual and the society at large.

Xuan (2015) elaborates an extended notion of presupposition in the categorization construed in lexis in a historical context on a cognitive basis. She discusses lexical presupposition in terms of ostensive inferences in ancient Chinese categorization: the functions of the radicals in their derivatives in Shuowen Jiezi. From her perspective, radicals work to constitute a ground-figure opposition with the most salient and characteristic features resembling statement assertions in sentences. Based on this, she develops a new approach to the study of pragmatic presupposition.

Masia (2016) investigates the processing of presupposition in discourse through the Event-related brain potential technique. She holds that while theoretical linguistics has largely described as the phenomenon of presupposition, there is little empirical investigation, mainly from behavioral studies. She employs the event-related potential technique to search for the brain signature of presupposition as opposed to assertion in discourse. From this point, her study is another breakthrough in the study of pragmatic presupposition.

\section{B. Previous Studies on Pragmatic Presupposition Based on Practical Application}

Just as studies on pragmatic presupposition from a theoretical perspective, studies on pragmatic presupposition based on practical application are also fruitful and yield a number of worthwhile and meaningful discoveries.

Wang (2013) studies the presupposition in advertising language with qualitative analysis. He divides pragmatic presupposition into five types and finds that pragmatic presupposition functions prominently. He further explains why pragmatic presupposition is adopted by the advertisers and elaborates the use of pragmatic presupposition. He hoped that the readers could recognize the useful information of advertisement and enjoy the special kind of communication.

Zeng (2012) holds that the production and interpretation of advertisements cannot be separated from both the advertisers' and its receivers' analysis and understanding of presupposition. She classified the presuppositions hidden in the advertisements into four categories according to the special characteristics of advertising languages and the previous research on the presupposition theory. From her perspective, the four types contact and compensate for one another and they can be utilized to help people understand the natural language of advertisements more completely and deeply.

Cong and Chou (2016) make a detailed analysis on the similarities and differences between pragmatic presupposition and semantic presupposition. From their point of view, semantic presupposition limits the research scale to the internal framework of a proposition and a sentence, while pragmatic presupposition considers the presupposition concerning the speakers, beyond the proposition or sentence. Thus, they advocate that the two presuppositions should be studied on, in that they complete and perfect each other. As a result, they conclude that it is more practical and dialectical to study the natural language through these two perspectives.

\section{Previous Studies on Cosmetic Advertisements}

Previous studies on cosmetic advertisements focus on the characteristics of cosmetic advertisements and translation method or strategy of advertisement translation. The following are some detailed information.

$\mathrm{Xi}$ (2013) holds that pragmatic presupposition, as a category based on the prototype theory, has the prototypical pragmatic presupposition and the non-prototypical pragmatic presupposition structure. She analyzes the pragmatic presupposition in advertisement translation in terms of prototype theory, in order to reveal that the successful translations of advertisements result from the wise usage of prototypic pragmatic presuppositions from the aspect of cultural background, language habits and social phenomena.

Zhang (2008) examines the translation of cosmetic advertisements. From his point of view, cosmetic advertisement is an important channel for the promotion of cosmetics. Based on the examples of world famous international brands and the Skopo theory, he makes a 
comparison between the feature of Chinese and foreign cosmetic advertisements. He further discusses different translation versions in terms of style and strategy and makes a summary of the pros and cons of the various translation versions.

Yan (2011) holds that advertisements have many distinctive features such as high-speed and broad transmission. In this case, cosmetic companies attach great importance to the language of advertisements, especially when the competition is fierce in the cosmetics industry. Under this circumstance, she analyzes all kinds of advertisements in the Fashion magazine, covering products like fashion clothing, luxuries, skin care products and so on. She also looks into how those advertisements catch the eyes of potential consumers, female consumers in particular.

\section{THEORETICAL BACKGROUND}

Presupposition is one of the most vital concepts in both pragmatics and philosophy. It was first introduced to pragmatics in 1970s and since then it has received wide attention both at home and abroad. This topic in pragmatics originates form the debates about the nature of reference in philosophy. These debates are the main concern in logical theory. They arise from the consideration of how to translate the referring expressions in natural language into restricted logical language. A presupposition is generally known as an implicit assumption about the world or background belief relating to an utterance whose truth is taken for granted in discourse.

\section{A. The Definition of Pragmatic Presupposition}

German philosopher Gottlob Frege, the architect of modern logic was the first one to deal with issues concerning the referring expressions in natural language. Strawson and Frege use semantic concepts such as truth and false value the analyze presuppositions. But the presuppositions they wrestle with are mainly concerned with statement, not sentence. Statements can be judged in communication, but not all sentences can be analyzed through truth value. As a result, presupposition develops into two major categories: semantic presupposition and pragmatic presupposition.

Pragmatic presuppositions are presuppositions that are analyzed from a pragmatic perspective rather than a semantic perspective. The definition of pragmatic presupposition is varied, which means that its definition is not universally acknowledged. The following are some definitions given by some famous scholars.

Keenan (1971) is the first linguist who put forward the concept of pragmatic presupposition. He thinks it can be best described as a relation between a speaker and the appropriateness of a sentence in a context. Stalnaker (1991) joined in in 1991 and offered his own opinion. From his perspective, pragmatic presupposition is made by persons rather than sentences, propositions or speech act. Yule (1996) holds that pragmatic presupposition is something the speaker assumes to be the case prior to making an utterance. Pecci (2000) defines it as the speaker's assumption and inferences about what is assumed to be true in the utterance rather than directly asserted to be true.

All of these definitions focus on two important concepts in particular: appropriateness and common ground. It means that if an utterance A pragmatically presupposes a proposition $\mathrm{B}$, A has to be appropriate and $\mathrm{B}$ is mutually known by all the participants involved in a conversation.

\section{B. The Characteristics of Pragmatic Presupposition}

As the definition of pragmatic presupposition is varied and assorted, so are the characteristics of pragmatic presupposition. During the development of pragmatic presupposition, more and more features and characteristics are discovered and put forward by numerous scholars and linguists. Levinson found out two basic properties of presupposition, namely, defeasibility and the projection problem. Later, some believe that the most important properties of pragmatic presupposition are appropriateness and common ground, while others believe that it also possess other properties such as subjectiveness and unidirectionality. However, this paper only focuses on the two most commonly received characteristics: appropriateness and common ground.

Appropriateness concerns the close relationship between presupposition and the context. Presuppositions are appropriate only if the presupposition indicated by the presupposition trigger is true. If the presupposition indicated is not true, the sentence in fact has no meaning at all. For example, if a man tells you John was shopping with his son, but you know that John is still a teenager, the sentence is meaningless and the presupposition is not appropriate. It is possible that the man who tells you this mistakes the boy with John as John's son, possibly because John really has a mature face.

Common ground is also an indispensible characteristic of presuppositions. For a presupposition indicated by presupposition triggers to be meaningful, the presupposition should be mutually known by the participants involved in the conversation. Mutual knowledge is very important. The background information should be understood by both the speaker and the hearer, in this case, the conversation can continue. Here is an example: A: Can you wait for John in the cinema? If the hearer has no idea who John is, this conversation is dead already. It is possibly the A assumes that the hearer knows John but she is too confidents about her own assumption.

\section{METHODOLOGY}

All the data used in this paper is either from the English official website of Lancôme or from the advertisements or ad videos online. The advertisements cover cosmetic products such as perfumes, essence and moisturizer. Five typical ones are chosen to detail the analysis. The followings are the five advertisements: The fragrance for treasured moments; The more I live, the younger I am; Your Skin Care Destination; You are unique, you are magnifique; I'm happier about myself than I've ever been. Confidence and energy make a woman stand out. 
All the advertisements will be analyzed generally in three steps. Firstly, the underlying meaning of the advertisement together with the presupposition it concerns with will be detailed. Secondly, consumers' expectation and thoughts about the advertised product will be examined. Finally, the comparison between the aforementioned two will lead to what kind of function and effect of the advertisement has. These advertisements are examined in three categories according to the functions of presuppositions in the cosmetic advertisements.

The study will take into consideration questions like: Do presuppositions in the cosmetic advertisements influence consumers' decisions? How do they contribute to the purchasing behavior of potential consumers? What are the functions of presupposition in cosmetic advertisements? Detailed analysis will be given in each segmented part.

\section{RESULTS AND DISCUSSION}

\section{A. Pragmatic Presupposition Makes Cosmetic Advertisements More Concise}

The main purpose of advertisements is to convey the information about the product and the functions of the product to the potential consumers. For cosmetic advertisements, the information is all about the magic features of the product. There is a great amount of information that the advertisers want to deliver, but it is impossible to include all of them. In this case, some information has to be hidden in one or two sentences. That is how presupposition works in the cosmetic advertisements, making them more concise. A sentence in an advertisement can presuppose rich information about the product.

\section{Example 1: The fragrance for treasured moments.}

This is the advertisement for one best-selling perfume of Lancôme - the Tresor series. Though short and concise, this sentence contains important information for the potential customers. It is not a stretch to find out that the advertisement presupposes that every woman has treasured moments in her life. For a girl first in love, a treasured moment may be the first date with the boy she has a crush on; for a capable white-collar, it may be a very important meeting with her seniors; for a middle-aged woman, it may be a reunion with her long-time-no-see friends or college classmates. In treasured moments, everyone wants to bring the best out of them and leave a wonderful impression on others. Then what do they need for such treasured moments? It is the fragrance. The fragrance refers to the perfume. Everything the advertisement wants to tell the customers is clear now: the perfume Tresor is suitable for all kinds of treasured moments in your life. In this way, the advertisement is concise but not plain or inane.

\section{B. Pragmatic Presupposition Makes Cosmetic Advertisements More Persuasive}

Every advertisement aims to persuade consumers to buy the advertised products. Thus, advertisers spare no effort in making their advertisements persuasive. Some resort to scientific data while some look into the psychological state of potential consumers. Many people know that what is said in the advertisement is not always true, but they sometimes can't help but believe it on impulse and throw their money on the magic product. Presupposition can be deployed to make the advertisement more persuasive since it presupposes something that the consumers are desperately looking for.

\section{Example 2: The more I live, the younger I am.}

Genifique, a world-known skin-care product, is one preessence developed by Lancôme. The advertisement above is for it. At first sight, the presupposition of this advertisement can be figured out: one looks young as she grows older. People are attracted by this kind of beautiful lies. Rationally, they certainly know that it is impossible. If a person looks younger as she grows older, it will violate the law of nature. Still, emotionally, they are greatly attracted by the presupposition. Beauty is an eternal theme in a woman's life. The advertisement makes full use of this mentality in the presupposition to attract female consumers, by telling them that you can be younger if you use the Genifique.

\section{Example 3: Your Skin Care Destination.}

This is the advertisement for one moisturizer: Lancôme Paris DreamTone. It presupposes that there is a skin care destination for every woman. That is exactly what the female consumers are looking for. Every woman accepts that she has to spend her whole life taking care of her skin since skin is always aging. They have to try all kinds of skin care products to find out the one that suits them best and can solve their skin problems perfectly. The best thing they want is a versatile product that can end their long search. And that is what the presupposition tells them: there is a skin care destination once you use the moisturizer.

\section{Pragmatic Presupposition Makes Cosmetic Advertisements More Attractive}

Only attractive advertisements can catch the eyes of consumers. Lively and vivid language is never a thing of the past. If an advertisement is plain and boring, no one is willing to give it a second look, let alone being attracted by the ad. Thus, advertisers should make their advertisements as attractive as possible. Some may use some figure of speech in the advertisements to make them more appealing; others may deploy some humor in the advertisement to make it more interesting.

Example 4: You are unique, you are magnifique.

Lancôme has another type of perfume called Magnifique, the above advertisement of which is thought-provoking. At first sight, consumers may get confused about the word magnifique. If they look it up in the dictionary, it is not difficult to find that magnifique means resplendent and brilliant. The point is that the name of this perfume is also Magnifique, making this advertisement so special. The presupposition of the advertisement is that Magnifique can make you both unique and magnifique. For women, they want to be the spotlight, they want to be unique. This perfume can just satisfy them. In addition, the presupposition makes the ad easier to remember, thus making it more attractive for potential consumers. 
Example 5: I'm happier about myself than I've ever been. Confidence and energy make a woman stand out.

This is the advertisement of another type of perfume. The presupposition is that I'm happier than I use to be after I use the perfume and women need confidence and energy in their life. Again, what is implied in the presupposition is just what female consumers are craving. Happiness, confidence and energy are pursued by every woman. And this perfume can make them happier. Why happier? It is because they find this perfume and they no longer need to wrong about that they are not confident and energetic anymore. In this way, presuppositions make advertisements more attractive.

\section{CONCLUSION}

This report examines the characteristics of advertising language of the French brand Lancôme. It also analyzes the impact of pragmatic presupposition on the advertising language and puts forward three functions of pragmatic presupposition concerning cosmetic advertising language, namely, presuppositions make advertisements more concise, more persuasive and more attractive.

Just like any other paper, this paper has its own limitation. Firstly, the amount and scope of data used are limited. All the data are about the same brand Lancôme and products concerned in the advertisement are not enough. Secondly, Lancôme is a high-end brand and some characteristics of its advertisements are typical of high-end brand. For example, the advertisements of high-end brands seldom consider the factor of price. But for the low-end brands and products, price is important and some advertisements may emphasize the low price of the product to attract consumers who have a tight budget on skin care products, like college students. Thus, future study should expand to a larger variety of brands and products. In this case, the study of pragmatic presupposition can be more productive and fruitful. In an addition, cosmetics companies should make a comprehensive study of the psychological state of the potential consumers and tactfully apply pragmatic presuppositions in the advertisements.

\section{REFERENCES}

[1] Qiang KANG, "The Use of Too as a Pragmatic Presupposition Trigger," Canadian Social Science, 2012(6), pp. 165-169.

[2] Philippe Schlenker, "Be Articulate: A Pragmatic Theory of Presupposition Projection," Theoretical Linguistics, 2008(3), pp. 157212.

[3] B. Lanre-Abass, "Racism and Its Presupposition: Towards a Pragmatic Ethics of Social Change," Human Affairs, 2010(4), pp. 364-375.

[4] Xuanwei Peng, "Pragmatic Presupposition in Chinese Categorization: A Figure-ground Angle of Radical's Roles in Shuowen Jiezi," Journal of Pragmatics, 2015, pp. 1-18.

[5] Viviana Masia, "Presupposition of New Information as a Pragmatic Garden Path," Journal of Neurolinguistics, 2016.

[6] Wangcong, A Pragmatic Analysis of Presupposition in English Cosmetic Advertising Language [M], Jilin University, 2013.

[7] Zeng Bihao, Study of Presupposition in Chinese and English Advertising Texts [D], Shanghai International Studies University, 2012 .
[8] Xi Tanping, "Pragmatic Presupposition in Translation of Advertising Language," Journal of Xi'an International Studies University, 2013(2), pp. 125-128

[9] Zhangchao, "Translation of Cosmetics Advertisements," Science \& Technology Information, 2008(20), pp. 252-253.

[10] Cong Rizhen, Chouwei, "Superposition and Complementarity Between Pragmatic Presupposition and Semantic Presupposition," Modern Foreign Language, 2016(5), pp. 594-604.

[11] Yanyan, "An Analysis on Features of Cosmetic Advertisements," News World, 2011(8), pp. 200-201. 